\title{
MIXING AHP WITH SOFT SYSTEMS THINKING IN THE EVALUATION OF RURAL TELECOMMUNICATIONS
}

\author{
D Petkov and T. Nepal \\ University of Natal, South Africa, petkov@comp.unp.ac.za \\ M L Sultan Technikon, Durban, South Africa, nepal@wpo.mIsultan.ac.za
}

Rural telecommunications in a developing country play both a technological and social role in the society. Their evaluation can be used for the assessment of the potential growth of certain sectors of the economy and for assessment of the needs for further development of their infrastructure.

The purpose of the framework is to provide a way for evaluation of the state of rural telecommunications in a regional context. As such it is viewed not just as an engineering phenomenon but also as an economic and social phenomenon. Its complexity requires the use of a mix of methods in a complementary manner. It is based on the combination of Soft Systems Methodology, Critical Systems Thinking following some ideas of Jackson(1997) ensuring, the guaranteeing of the interests of the poor and the weak in the rural environment, and the Analytic Hierarchy Process by Saaty.

The nature of the framework, proposed in this research is "soft", following Checkland (1995). He points out that, there is a critical difference "between on the one hand an approach which assumes the world to be a complex of systems, some of which may be malfunctioning, and on the other an approach which makes no assumptions about the nature of the world, beyond assuming it to be complex, but assumes that the process of enquiry can be organised as a system of learning. The approach which assumes the world to be systemic is 'hard'; the approach which assumes that the process of enquiry can be systemic is 'soft'"(Checkland,1995:5354). On the basis of the nature of the framework, one can view it as a learning process leading to better understanding of rural telecommunications.

Rural telecommunications evaluation is a complex activity, involving various stakeholders with views that do not necessarily coincide. Therefore the applicability of a pluralist approach is justified. In line with Checkland (1995), Jackson (1997) and others, this research acknowledges the social dimension of the problem situation and the multiplicity of interpretations related to it.

To the best of the knowledge of the authors, it is the first systemic analysis of the issue of the assessment of rural telecommunications, incorporating a combination of soft and hard approaches to it. These interact together while operating within different paradigms, enabling critique to be managed between the paradigms and not controlled above the paradigms (Jackson, 1997:6).

One can argue that the components of the framework are parts of well-known approaches. However, the combination of the techniques concerned and the way they are used has not been reported before in the literature to such a problem. The paper will explore the first experience of the authors applying the framework to real cases of evaluation of rural telecommunications within a large rural area in South Africa.

\section{References}

Checkland P. (1995), Model Validation in Soft Systems Practice, Systems Research, 12(1), 47-54.

Jackson M. C. (1997). Towards Coherent Pluralism in Management Science, working paper No. 16, Lincoln school of Management.

Saaty T.(1994). Fundamentals of Decision Making and Priority Theory with the Analytic Hierarchy Process, RWS Publications, Pittsburgh. 